\title{
Technical Considerations of Endoscopic Subureteral Injection for the Treatment of Vesicoureteral Reflux
}

\author{
Mi Mi Oh, Hyun Chul Kim, Jae Hyun Bae, Hong Seok Park, Je Jong Kim and Du Geon Moon* \\ Department of Urology, Guro Hospital, Korea University College of Medicine, Seoul, Korea
}

\begin{abstract}
The purpose of this study was to assess the long-term efficacy and the cause of failure in endoscopic subureteral injection for vesicoureteral reflux. For 5 years, a total of 73 patients (96 ureters) with primary grades I to V VUR were treated by one operator using subureteral injection of polydimethylsiloxane (PDS) and followed-up for more than 1 year. Cure was defined as an absence of VUR on voiding cystourethrography at 3 months after injection. Second and third injection was done for the failed cases. Statistical analyses were performed using the chi-square test. Endoscopic subureteral injection of PDS showed high success rate $(82.3 \%)$ after single injection, $98 \%$ after second injection for the failed cases. Correction by grade was $75 \%, 83 \%, 89 \%, 83 \%$, and $77 \%$ for grade I to $\mathrm{V}$, respectively. In 17 units of second injection, cystoscopy showed mound displacement in 9 units, no volcano appearance but rather a broad elevation in 5 units, mound extrusion in 2 units, and distal ureteral fistula in 1 unit. Among 17 failed units, 58.8\% (10/17) occurred in the first 18 months, meanwhile, failure rate decreased to $9.5 \%(7 / 74)$ in later 42 months during the 5 years' practice in our institute. In contrast to the generally accepted concept, the primary grade was not the main cause of success. Besides the primary reflux grade, available position according to the characteristics of the patients, injection method, the operator's skill and experience greatly affect the success rate.
\end{abstract}

Keywords: Vesicoureteral reflux; Endoscopy; Polydimethylsiloxane

\section{Introduction}

Since the introduction of polydimethylsiloxane (PDS, Macroplastique $^{\circledR}$, Uroplasty Inc. Geleen, Netherlands) in 1994 and Food and Drug Administration approval of dextranomer/hyaluronic acid (Dx/HA, Deflux ${ }^{\mathbb{R}}$, Q-Med, Uppsala, Sweden) copolymer in 2001, the endoscopic management of VUR has become popular as a first line treatment. This minimally invasive procedure made it

Accepted for Publication: March 18, 2008

*Correspondence: Du Geon Moon, 152-703, Department of Urology, Korea University, Guro Hospital, Phone: 02-2626-3201, FAX: 02-2626-1321, E-mail: dgmoon@korea.ac.kr an attractive alternative to prolonged antibiotic prophylaxis and open surgery for many parents and surgeons. But it is a challenging for the beginner and the role of endoscopic injection for VUR is still debated compared to open surgery in the aspects of success rates and lack of long-term result. Overall success rate of endoscopic treatment were reported as $70 \sim 80 \%$ for primary uncomplicated VUR but higher grade of reflux being lower. ${ }^{1-3}$ Recently, with more experience, the success rate of endoscopic management of VUR was greatly increased, and also, Kirsh et $\mathrm{al}^{4}$ introduced a technique called 'The modified STING', improving the success rates of high grade of VUR. 
We describe our experience of endoscopic subureteral PDS injection, and the efficacy and technical causes of failure cases.

\section{Materials and Methods}

This retrospective study included 30 boys and 43 girls of 2 to 15 years old (mean age 8) with a total of 96 ureters in whom endoscopic injection of PDS for VUR from 2001 to 2005 and followed until 2007. Mean follow-up period was 21.5 (16 to 40) months. Patients with congenital urogenital anatomical anomaly rather than VUR and those associated with neurogenic bladder were excluded from this study. Each patient underwent preoperative evaluation with a voiding cystourethrography, renal ultrasound, dimercapto-succinic acid (DMSA) scan and urine culture. All procedures were performed by one investigator. A $9.5 \mathrm{Fr}$ pediatric cystoscope transurethrally with an offset lens was used in all cases. Endoscopic surgery was performed under the general anesthesia and the bulking agent was injected at 6 o'clock of ureteral orifice with 4 Fr PDS injection needle. Initially the needle was plunged to a depth of $5 \sim$ $10 \mathrm{~mm}$ into the bladder mucosa and injection was performed until convex elevation around the ureteral orifice was made. Special care was taken, as the injection material might leak during multiple injections. Endoscopic photographs which included pre and post
PDS injections were taken to document their anatomy for every patient. Our clinical protocol includes renal ultrasound at 1 week postoperatively to evaluate the presence of hydronephrosis, and voiding cystourethrography (VCUG) and bladder ultrasound at 3 months to confirm whether VUR is resolved and volume loss of injected PDS existed (Fig. 1). Low-dose antibiotic prophylaxis was continued until resolution of VUR has been confirmed radiographically. The grade and laterality of VUR by VCUG before and after treatments were used to determine the success of the therapy. Since Aug 2004, we executed a 'modified STING' procedure by $\mathrm{Kirsch}^{4}$ in high grade VUR. The modified technique differed as the PDS implant was injected submucosally after hydrodistention of intramural ureter at a 6 o'clock position within the ureteral lumen of the affected renal unit until coaptation of the luminal mucosa was achieved.

\section{Results}

\section{The results of endoscopic management}

The grade of reflux was I, II, III, IV and V in 4, 12, 18,36 and 26 ureteral units respectively. Reflux was unilateral and bilateral in 50 (68.5\%) and 23 (31.5\%) cases, respectively. For each ureter, mean PDS volume of $0.80(0.5 \sim 1.5)$ cc was injected. Mean operation time was $15.97 \pm 4.32$ minutes.
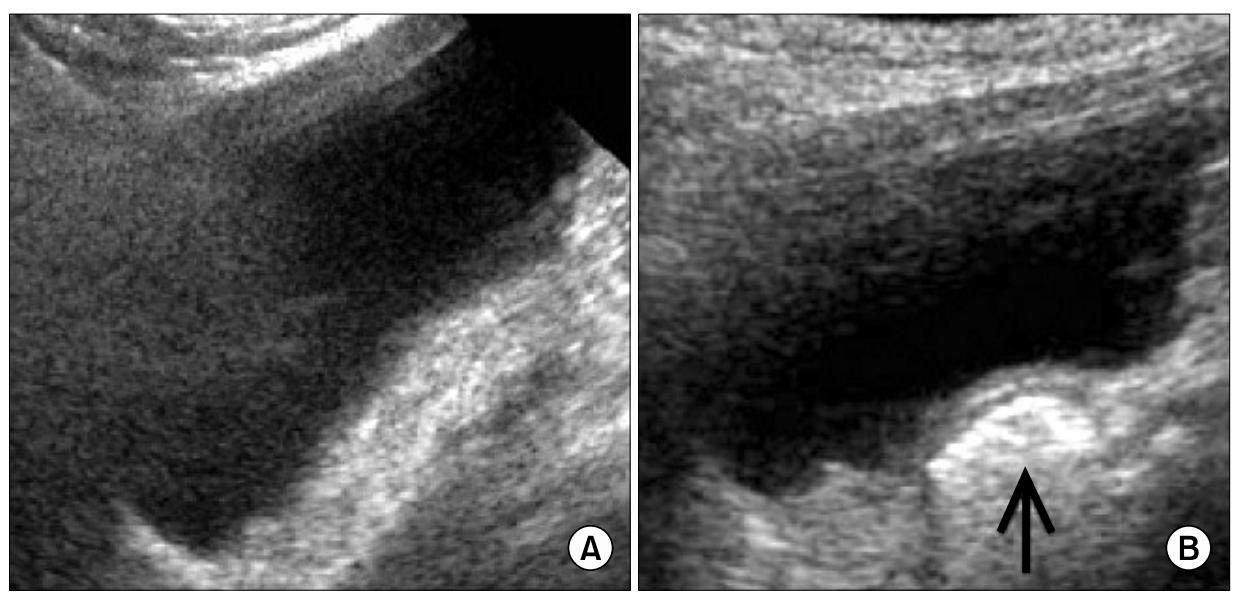

Fig. 1. Sonographic finding of the urinary bladder. (A) No specific echogenic was noted at the right ureteral orifice on preoperative sonography. (B) An echogenic nodule (arrow) of injected PDS is noted on post-operative sonography. 
After a single injection, reflux was corrected in 79 of $96(82.3 \%)$ ureteral units and 58 of $73(79.5 \%)$ children. Correction by grade was $75 \%, 83 \%, 89 \%, 83 \%$, and $77 \%$ for grade I to $\mathrm{V}$, respectively (Table 1). This result shows that grade is not the major determining factor of success rate of endoscopic injection. With repeated injection, reflux was corrected in 15 of 17 (88.2\%) ureteral units and 13 of $15(86.7 \%)$ children. After second injection, 2 children had recurrence of reflux and needed a third injection. The reflux had all resolved after the third injection. De novo hydronephrosis with left flank pain was developed at one case,

Table 1. Results of endoscopic subureteral injection for vesicoureteral reflux patients

\begin{tabular}{lcccc}
\hline $\begin{array}{l}\text { Reflux } \\
\text { grade }\end{array}$ & $\begin{array}{c}\text { No. of reflux } \\
\text { ureteral units }\end{array}$ & $\begin{array}{c}\text { No. of improved } \\
\text { ureters }(\%)^{*}\end{array}$ & $\begin{array}{c}\text { No. of unchanged } \\
\text { ureters after } 1^{\text {st }} \text { injection (\%) }\end{array}$ & $\begin{array}{c}\text { No. of unchanged ureters } \\
\text { after } 2^{\text {nd }} \text { injection }(\%)\end{array}$ \\
\hline I & 4 & $3(75.0)$ & $1(25.0)$ & $0(0)$ \\
II & 12 & $10(83.3)$ & $2(16.7)$ & $0(0)$ \\
III & 18 & $16(88.9)$ & $2(11.1)$ & $0(0)$ \\
IV & 36 & $30(83.3)$ & $6(16.7)$ & $0(0)$ \\
V & 26 & $20(76.9)$ & $6(23.1)$ & $2(10)$ \\
Total & 96 & $79(82.3)$ & $17(17.7)$ & $2(11.8)$ \\
\hline
\end{tabular}

*: no statistical difference in improved rates between each vesicoureteral reflux grade by chi-square test $(p=0.759)$
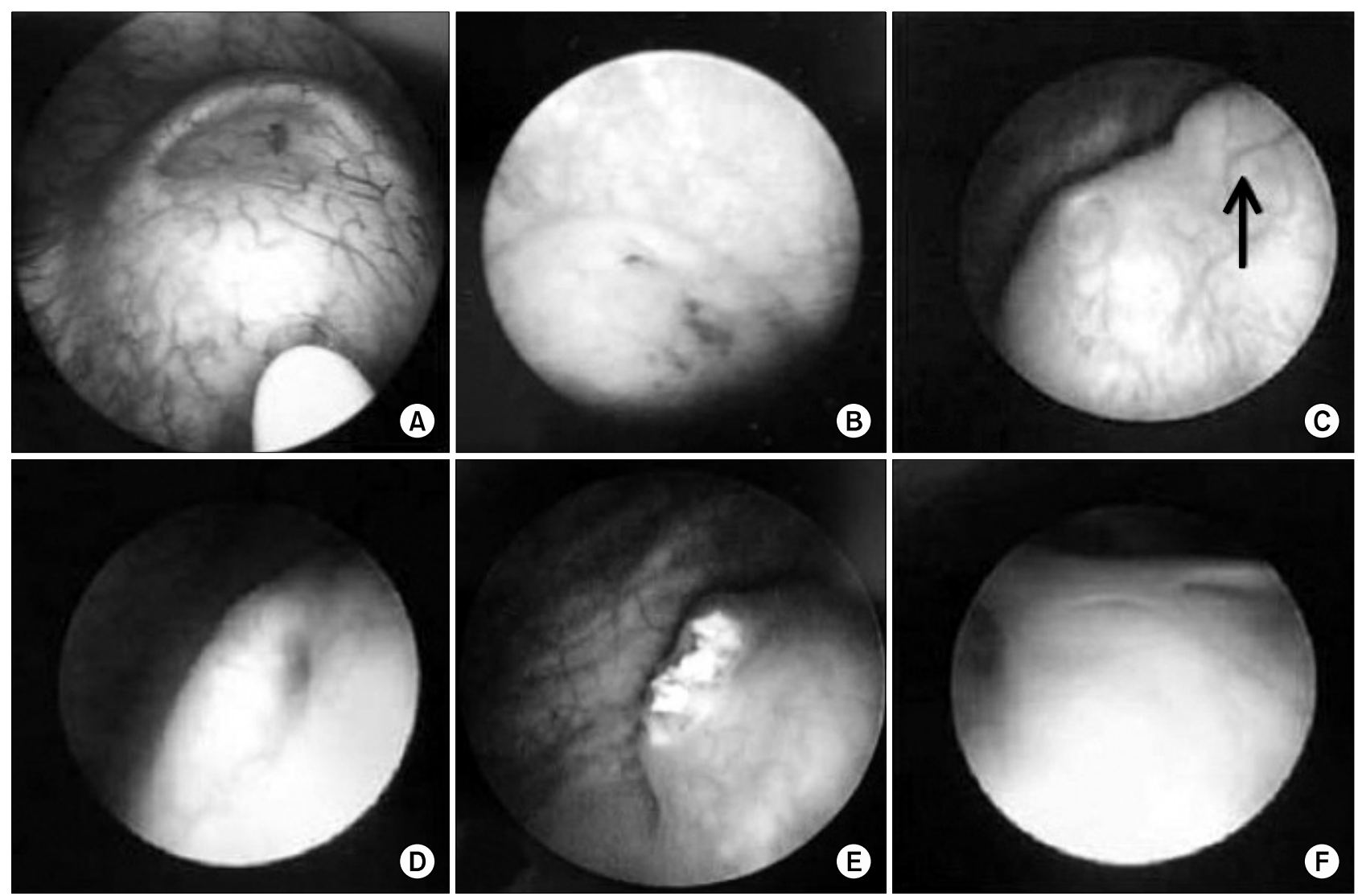

Fig. 2. Operative cystoscopic findings. (A) Creation of competent ureteral orifice by cystoscopic submucosal injection of PDS. (B) Competent ureteral orifice on the top of a 'volcano' after injection of PDS. (C) Incompetent ureteral orifice; a main mound (arrow) is seen above the ureteral orifice. (D) Incompetent ureteral orifice; a mound is still poorly seen around ureteral orifice at $5 \sim 7$ o'clock. (E) Extrusion of PDS is seen due to mucosal necrosis after overcorrection. (F) Ureteral fistula at the right. ureteral orifice is seen. It might be the result of complete extrusion of PDS after overcorrection. 
but it was improved at follow-up period. No other significant complication occurred.

\section{The cause of failure of endoscopic management}

Second injection was done in 17 of 96 (17.7\%) ureteral units of failed single injection. Cystoscopy showed mound displacement in 9 cases, no volcano appearance but rather a broad elevation in 5 cases, mound extrusion in 2 cases, and distal ureteral fistula in 1 case. The ideal shape of ureteral orifice after endoscopic PDS injection could be a volcano shaped orifice with good elevation and coaptation (Fig. 2A, 2B). In 9 cases, mound displacement of implant that was migrated to a medial or caudal direction in relation to the ureteral orifice was observed at cystoscopy (Fig. $2 \mathrm{C})$. In 5 cases the lesion surrounding ureteral orifice was slightly elevated, but had not a volcano shape or obstruction. Additionally, PDS implant remained only a little volume at bladder ultrasound. This leads us to suspect that the injection was correctly accomplished at a normal site but too deeply done (Fig. 2D). In 2 cases, mucosal rupture of ureteral orifice was developed (Fig. $2 \mathrm{E})$. In one case, a fistula was found at ureteral orifice and implant material had disappeared (Fig. 2F). It is suspected that injected volume was too large and implant was placed more superficially, so the pressure necrosis of urothelium let the implant leak out.

\section{The relation between the operation time and suc- cess rate}

To investigate whether procedural failure was related to proficiency, the number of cases and success rates were compared between different periods. In early 18 months, 22 cases were operated, among which 12 $(54.5 \%)$ of them were successfully treated and 10 (45.5\%) ureters failed (Table 2). In contrast, latter 18 months, 74 cases were operated, whereas 67 (90.5\%) were successfully treated and 7 (9.5\%) failed. Comparing before and after 18 months, success rates showed statistically significant difference $(\mathrm{p}<0.01)$. Thereafter, the authors concluded that the proficiency was more
Table 2. Comparison of the results of endoscopic subureteral injection between before and after 18-month during enrolled period

\begin{tabular}{lccc}
\hline & $\begin{array}{c}\text { No. of reflux } \\
\text { ureteral units }\end{array}$ & $\begin{array}{c}\text { No. of improved } \\
\text { ureters }(\%)^{*}\end{array}$ & $\begin{array}{c}\text { No. of } \\
\text { unchanged } \\
\text { ureters (\%) }\end{array}$ \\
\hline Initial 18 months & 22 & $12(54.5)$ & $10(45.5)$ \\
After 18 months & 74 & $67(90.5)$ & $7(9.5)$ \\
\hline
\end{tabular}

*: statistical difference in improved rates between before and after 18 -month by chi-square test $(p<0.01)$

important than the grade of VUR.

\section{Discussion}

We describe the experience of endoscopic correction of VUR by one operator for 5 years and classified the cause of failure on follow-up cystoscopic findings and depicted the usefulness of the Modified STING technique for the successful endoscopic correction in high grade VUR.

For less invasiveness, short hospitalization and no significant complications of endoscopic correction of VUR, repeated injection can be done in cases of failure after single injection. Aboutaleb et al. reported that not only the success of PDS (82\%) was significantly lower than that of open surgery (98\%) but the injection procedures required shorter operative times (average 15 minutes) and anesthesia times without complications. ${ }^{5}$ Herz at al reported $81 \%$ success rate of 112 refluxing ureters after single PDS injection, and 90\% success rate after second PDS injection. ${ }^{6}$ In our series, the success rate was $82.3 \%$ in 96 ureteral units after a single injection and $88.2 \%$ in 17 ureteral units with second injection and $100 \%$ in third injection. Although complete cure was achieved with repeated endocopic injection, further study about the efficacy of repeated injection in failed cases is necessary.

In this study, de novo hydronephrosis with left flank pain developed in one case, but disappeared after conservative observation alone. Aboutaleb et al. ${ }^{7}$ reported observation alone was sufficient for de novo hydro- 
nephrosis as a complication and the rate of de novo hydronephrosis was significantly less in the PDS group than extravesical ureteral reimplantation group. Conversely, David et al. reported $0.7 \%$ of patient with Dx/HA injection developed symptomatic ureteral obstruction and necessitated surgical intervention. ${ }^{8}$

The precise mechanism by which endoscopic injection corrects reflux remains indeterminate. Proposed mechanism have included improved fixation of the ureter to the trigonal musculature, improved backing of the ureterovesical junction by the bulking agent and decreased ureteral luminal caliber by the mound. ${ }^{9}$ But the operator can assume the causes of failure on cystoscopic findings of repeated injection. Lavella et al. ${ }^{1}$ reported that mound morphology, but not other factors including grade, volume injected, endoscopic appearance after injection and presence or voiding dysfunction, was the only statistically significant predictor of a success outcome. It is also reported that injection failure attributed from an absent mound to low injection volumes and/or multiple punctures during the initial injection. ${ }^{10}$ Detrusor overactivity has been proposed as an etiology for the mound displacement and implicated dysfunctional voiding maybe responsible for mound displacement. ${ }^{11}$

In this study, we also classified the causes of failure based on cystoscopic findings. First, mound displacement of implant developed. The injected materials migrated to a medial or caudal direction in relation to the ureteral orifice. It might be due to the bulking agent being injected in the wrong position because of poor operation field especially in boys of less than 1 year. Second, volume of the injected PDS was lost and resulted in loss of volcano shape of periureteral orifice mucosa. We also could anticipate loss of implant volume from bladder ultrasound. The causes of volume loss might be due to inadequate volume or injection of too deeply under the mucosa. Third, mound extrusion due to mucosal necrosis with implants injected too shallowly. Fourth, abnormal bladder contraction due to detrusor overactivity might be the reason. The leading cause of failure of endoscopic injection therapy for VUR might be the technical failure.

To improve the success rat, it is important that the implant should be placed at accurate location, with optimal volume required for elevation and coaptation of ureteral orifice. Kirsch et al. ${ }^{4}$ reported the results using modified STING technique that success rates were significantly $(\mathrm{p}<0.01)$ greater for the modified STING (92\%) vs. the standard STING (79\%) with dextranomer/ hyaluronic acid copolymer. Their modified STING technique use ureteral hydrodistention, that is, bladder is filled to half to three-quarters volume to permit visualization of the ureter and avoid distortion and tension within the submucosal layer of the ureter secondary to over distention. We also performed this modified STING technique for endoscopic injection on high grade VUR since the August of 2004. In our experience, the lower ureters are usually dilated in high grade reflux which enables the operator to do the modified STING technique easily. Unlike the generally accepted concept, high grade refluxing ureter is easier to do the modified STING technique with dilated lower ureters because it ables the injection needle to be inserted into the ureteral orfice under the submucosal tunnel. Recently high success rate is achieved even in grade $\mathrm{V}$ reflux with endoscopic treatment and endoscopic treatment is recommended as first line treatment for the treatment of high grade VUR. ${ }^{12}$

It means that accurate procedures from operator's experience are needed to improve the results of endoscopic injection rather than the grade of reflux. Kirsch ${ }^{3}$ and Capozza ${ }^{13}$ reported that more experience yields a higher success rate, which is likely more noticeable in patients with higher reflux grades and even grade IV VUR and VUR in complex anatomical situations can be successfully treated by endoscopy. It was proved by our results that higher failure rate was noted in early 18 months and the failure rate had markedly decreased in late 42 months. Also preoperative urodynamic study has been suggested because abnormal bladder contraction could be a cause of failure. ${ }^{11}$ These issues will 
require further study with long-term follow-up and more data.

In conclusion, endoscopic treatment of VUR with PDS using modified STING technique showed high success rate after single injection and after second injection for the failed cases in the first injection. In contrast to the generally accepted concept, the primary grade was not the main cause of success. In consideration of the cystoscopic findings in failed injection, the operator's technical failure may be the main cause. Besides the primary reflux grade, available position according to the characteristics of the patients, injection method, the operator's skill and experience greatly affect the success rate. In high grade reflux, the injection technique of 'modified STING' could be easily done and helpful for the successful injection.

Therefore, although long-term results will be need, we consider surgeon's experiences and exact practices might be the most important factors for endoscopic treatment for VUR to be selected as a primary treatment option instead of open ureteral reimplantation.

\section{References}

1. Lavelle MT, Conlin MJ, Skoog SJ. Subureteral injection of deflux for correction of reflux: analysis of factors predicting success. Urology 2005;65:564-7.

2. Perez-Brayfield M, Kirsch AJ, Hensle TW, Koyle MA, Furness P, Scherz HC. Endoscopic treatment with dextranomer/hyaluronic acid for complex cases of vesicoureteral reflux. J Urol 2004;172:1614-6.
3. Kirsch AJ, Perez-Brayfield MR, Scherz HC. Minimally invasive treatment of vesicoureteral reflux with endoscopic injection of dextranomer/hyaluronic acid copolymer: the Children's Hospitals of Atlanta experience. J Urol 2003;170:211-5.

4. Kirsch AJ, Perez-Brayfield M, Smith EA, Scherz HC. The modified sting procedure to correct vesicoureteral reflux: improved results with submucosal implantation within the intramural ureter. $J$ Urol 2004; 171:2413-6

5. Aboutaleb H, Bolduc S, Khoury AE, Upadhyay J, Bägli DJ, Farhat W. Polydimethylsiloxane injection versus open surgery for the treatment of vesicoureteral reflux in complete duplex systems. J Urol 2003;170:1563-5.

6. Herz D, Hafez A, Bagli D, Capolicchio G, McLorie G, Khoury A. Efficacy of endoscopic subureteral polydimethylsiloxane injection for treatment of vesicoureteral reflux in children: a North American clinical report. J Urol 2001;166:1880-6.

7. Aboutaleb H, Bolduc S, Upadhyay J, Farhat W, Bägli DJ, Khoury AE. Subureteral polydimethylsiloxane injection versus extravesical reimplantation for primary low grade vesicoureteral reflux in children: a comparative study. J Urol 2003;169:313-6.

8. Vandersteen DR, Routh JC, Kirsch AJ, Scherz HC, Ritchey ML, Shapiro E, et al. Postoperative ureteral obstruction after subureteral injection of dextranomer/hyaluronic acid copolymer. $J$ Urol 2006;176: 1593-5.

9. Joyner BD, Atala A. Endoscopic substances for the treatment of vesicoureteral reflux. Urology 1997;50:489-94.

10. Higham-Kessler J, Reinert SE, Snodgrass WT, Hensle TW, Koyle MA, Hurwitz RS, et al. A review of failures of endoscopic treatment of vesicoureteral reflux with dextranomer microspheres. J Urol 2007;177: 710-4.

11. Capozza N, Lais A, Matarazzo E, Nappo S, Patricolo M, Caione P. Influence of voiding dysfunction on the outcome of endoscopic treatment for vesicoureteral reflux. $J$ Urol 2002;168:1695-8.

12. Menezes MN, Puri P. The role of endoscopic treatment in the management of grade $\mathrm{v}$ primary vesicoureteral reflux. Eur Urol 2007;52:1505-9.

13. Capozza N, Lais A, Nappo S, Caione P. The role of endoscopic treatment of vesicoureteral reflux: a 17 -year experience. J Urol 2004; 172:1626-8. 